\title{
The Effect of School-Based Intervention on Obese and Overweight Students in Urmia, Iran
}

\author{
Baratali Rezapour $^{1,2}$, Firoozeh Mostafavi ${ }^{3}$ \& Hamidreza Khalkhali ${ }^{4}$ \\ ${ }^{1}$ Department of Health Education \& Health Promotion, Isfahan University of Medical Sciences, Isfahan \\ ${ }^{2}$ Urmia University of Medical Sciences, Urmia, Iran \\ ${ }^{3}$ Department of Health Education \& Health Promotion, Isfahan University of Medical Sciences, Isfahan, Iran \\ ${ }^{4}$ Inpatient's Safety Research Center, Urmia University of Medical Sciences, Urmia, Iran \\ Correspondence: Firoozeh Mostafavi, Department of Health Education \& Health Promotion, Isfahan University \\ of Medical Sciences, Isfahan, Iran. Tel: 98-913-211-8364. E-mail: f_mostafavi@yahoo.com
}

Received: April 21, 2016 Accepted: June 7, 2016 Online Published: July 29, 2016

doi:10.5539/gjhs.v9n3p283 URL: http://dx.doi.org/10.5539/gjhs.v9n3p283

\begin{abstract}
Objective: Obesity is an important concern for both adults and students. The study evaluates the effect of school-based intervention (SBI) on sedentary life style (SLS), physical activity (PA) and body mass index (BMI) among the students in Urmia, Iran.
\end{abstract}

Methods: The study was undertaken from 31 December 2013 to 21 June 2014. A total of 80 male students were randomly selected from single-sex junior high schools of the two existing districts in Urmia. They were assigned to two groups of intervention and control (each 40). SBI was performed on intervention group during 6 months. The essential parameters for evaluating the effects of SBI on SLS, ADL and BMI of students were used.

Results: There was a significant difference between the two groups for the cycling $(\mathrm{P}<0.001)$ and walking $(\mathrm{P}=0.003)$ in leisure time and TV watching time $(\mathrm{P}=0.007)$ in the intervention group. After the intervention a decrease was found in the BMI, but it wasn't significant $(\mathrm{p}>0.05)$.

Conclusions: According to the obtained results, the SBI had a positive effect on the improvement of ADL but the reverse was true about SLS in obese and overweight students. More comprehensive randomized experiments must perform to explain the effects of long time SBI on the BMI of the obese and overweight students.

Keywords: obesity, school-based services, activities of daily living, sedentary lifestyle

\section{Introduction}

In the present century obesity and overweight are the most important concern in the world. The highest increase in the prevalence of obesity in most countries has been of global concern (Djalalinia et al., 2015). Obesity and overweight are the world's fifth cause of mortality, and 2.6 million people die of this disorder annually (Asghar et al., 2015). According to certain Iranian national studies in people $<18$ year the prevalence of obesity varies between 5.0-13.5, and 3.2-11.9 in males and females, respectively (Jafari-Adli et al., 2014). The nationwide school-based study which conducted in students of 6-18 years old showed that based on the WHO growth curves, 9.7\% and 11.9\% were overweight and obese, respectively (Roya et al., 2013). The importance of activities of daily living (ADL) (including walking and cycling in leisure time) in reducing rates of chronic diseases has been proved (Jafari-Adli et al., 2014). Schools must develop PA among students (McKenzie et al., 1996). SBI has shown promise in helping to reduce students' SLS, including TV-watching time, by providing means for parents and students to monitor and budget the time that students spend on TV-watching and increase PA during physical education (PE) classes at high school (McKenzie et al., 1996). Although this issue has been variously studied by different scholars in the context of Iran, there is almost no study which approaches the issue by using the Baecke questionnaire in West Azerbaijan and considered ADL and SLS. Our study aimed at assessing the effect of SBI on ADL and SLS in junior students of high school in Urmia. 


\section{Methods}

\subsection{Design and Setting}

This study was a quasi-experimental SBI that performed in Urmia, Iran. The ethical code of study was grant No: 393847. Urmia has two education districts. The unit of randomization was school. Four high schools were randomly chosen from two states. Schools were randomly allocated to control or interventional groups. Both parents and students filled out the written consent form before participating in the study. Researcher educated them that all the personal identifiers were confidential. Data was collected in three steps: before intervention, 3 and 6 months after intervention. All seventh-grade students of selected schools completed the baseline questionnaire. All the required information was recorded on questionnaires by the first researcher. The statistical analyses between variables carried out to determine effect of SBI on ADL and SLS and BMI in junior students of high school in Urmia. The intervention group participated in explaining classes.

\subsection{Population}

A total of 80 seventh-grade male students were randomly selected from single-sex junior high schools of the two existing districts in Urmia, Iran. They were assigned to two groups of intervention and control (each 40). Their ages ranged 12-14 years $(13.10 \pm 0.81)$. They were non-diabetic, non-hypertensive, and also overweight or obese according to WHO 2007 table (De, Onyango, Borghi, Siyam, Nishida, \& Siekmann, 2007). Those whose were BMI $\geq 85$ th percentile regarded overweight and obese. The exclusion criteria included students with visible physical disability, medical disorders like thyroid, renal, diabetes mellitus type II, adrenal disorders and/or unwilling.

\subsection{Instrument}

The instruments of data collection included tripartite questionnaires: 1.demographic characteristics 2. Basic anthropometric data that included weight measured $(\mathrm{kg})$ to the nearest $0.1 \mathrm{~kg}$ using a digital scale (Seca Model, made in Germany); height $(\mathrm{m})$ with light clothes and without shoes, measured to the nearest $0.1 \mathrm{~cm}$ using a portable stadiometer 3. Baecke Questionnaire. The components of Baecke questionnaire were: work activity, sport and leisure index (alpha Cronbach was $0.881,0.726$ and 0.675 respectively), included 16 items, that it's validity proved in previous studies (Baecke, Burema, \& Frijters, 1982; Mirzaee Vishgaee, Rahmani Niya, \& AR., 2014; Ono et al., 2007; Peter \& Bandmann, 2008; Saris, Snel, Baecke, van Waesberghe, \& Binkhorst, 1977; Tofighi, Babaei, Eloon Kashkuli, \& Babaei, 2014).

\subsection{Intervention}

SBI carried out to change the school situation and to increase PA among children by practical implementation and oral explanation by collaborative methods, role playing, lectures and group discussions in 6 sessions (held for one hour per session). These educational methods performed to learn the behavioral skills for copying with obesity and overweight by involving students in ADL during school break time. Environmental change activities included preparation sport tools by communication increase between/among students, by sports team and promotion of ADL by parent-teacher association and school health staff.

\subsection{Statistical Analysis}

In this study data was analyzed using SPSS version 16. Results were analyzed using Analysis of Covariance (ANCOVA). Chi-square test was applied to compare behavior PA (ADL and SLS) between intervention and control groups.

\section{Results}

The BMI, SBI, TV-watching time, CLT, WLT and SAW of participants in the both control and intervention the group were analyzed by chi-square test (Table 1). Finding showed that TVWT was decreased in the intervention schools at time 6 month after intervention in comparison baseline $(\mathrm{P}=0.007)$. It was determined that in SAW there was a significant difference between before and 6 months after the SBI in the intervention group $(\mathrm{p}=0.022)$ (Table1). Also the CLT was higher in the intervention group 6 months after intervention $(\mathrm{P}<0.001)$. There was no significant difference between students in the demographic variables (such as age, parents' literacy, and job) at the baseline. Table 2 indicates although BMI decreased in 6 months after SBI, there wasn't significant difference between BMI at the baseline and six months after the intervention. Because parents of obese and overweight students worried about their children so they encouraged their children in both groups to do many treatment and physical activities. Furthermore, the BMI of the students in the control group reduced. 
Table 1. Distribution of components of ADL and SLS variables at the baseline 3 and 6 months after intervention

\begin{tabular}{|c|c|c|c|c|c|c|c|c|}
\hline \multirow[t]{2}{*}{ Variables } & \multirow[t]{2}{*}{ Response } & \multirow[t]{2}{*}{ Point } & \multicolumn{2}{|l|}{ Baseline } & \multicolumn{2}{|c|}{$\begin{array}{l}3 \text { months } \\
\text { intervention }\end{array}$} & \multicolumn{2}{|c|}{$\begin{array}{l}6 \text { months } \\
\text { intervention }\end{array}$} \\
\hline & & & Inter* & Control** & Inter & Control & Inter & Control \\
\hline \multirow{3}{*}{ TVWT } & Never or seldom (\%) & $1-2$ & $16(40)$ & $23(57.5)$ & $19(47.5)$ & $22(55)$ & $34(85)$ & $23(57.5)$ \\
\hline & Sometimes or always $(\%)$ & $3-5$ & $24(60)$ & $17(42.5)$ & $21(52.5)$ & $18(45)$ & $6(15)$ & $17(42.5)$ \\
\hline & P-value & & 0.117 & & 0.502 & & 0.007 & \\
\hline \multirow{3}{*}{ SAW } & Never or seldom (\%) & $1-2$ & $20(50)$ & $22(55)$ & $31(77.5)$ & $25(62.5)$ & $29(72.5)$ & $19(47.5)$ \\
\hline & Sometimes or always $(\%)$ & $3-5$ & $20(50)$ & $18(45)$ & $9(22.5)$ & $15(37.5)$ & $11(27.5)$ & $21(52.5)$ \\
\hline & P-value & & 0.654 & & 0.143 & & 0.022 & \\
\hline \multirow{3}{*}{ CLT } & Never or seldom $(\%)$ & $1-2$ & $26(65)$ & $18(45)$ & $17(42.5)$ & $23(57.5)$ & $7(17.5)$ & $22(55)$ \\
\hline & Sometimes or always (\%) & $3-5$ & $14(35)$ & $22(55)$ & $23(57.5)$ & $17(42.5)$ & $33(82.5)$ & $18(45)$ \\
\hline & P-value & & 0.072 & & 0.180 & & 0.000 & \\
\hline \multirow{3}{*}{ WLT } & Never or seldom $(\%)$ & $1-2$ & $17(42.5)$ & $20(50)$ & $16(40)$ & $19(47.5)$ & $11(27.5)$ & $24(60)$ \\
\hline & Sometimes or always $(\%)$ & $3-5$ & $23(57.5)$ & $20(50)$ & $24(60)$ & $21(52.5)$ & $29(72.5)$ & $16(40)$ \\
\hline & $\mathrm{P}$-value & & 0.501 & & 0.499 & & 0.003 & \\
\hline
\end{tabular}

Inter $^{*}=$ intervention group, control**= control group, TVWT (TV watching in leisure time), SAW (sit at work) CLT (cycling in leisure time) WLT (walking in leisure time).

Table 1 shows the effect of SBI on the components of ADL constructs (i.e., CLT and WLT) and the components of SLS constructs (i.e., SAW and TVWT) 3 and six months after the intervention in the intervention and control group. Chi-square shows that in the intervention group there is a significant increase in the components of ADL six months after intervention whereas there is a significant decrease in the components of SLS at the same time.

Table 2. Mean and SD of BMI in both intervention and control groups in the baseline and 6 months after the intervention

\begin{tabular}{llll}
\hline \multirow{2}{*}{ Group } & Baseline & & $\mathbf{6}$ months after the intervention \\
\cline { 2 - 2 } Intervention & Mean $\pm \mathrm{SD}$ & & Mean $\pm \mathrm{SD}$ \\
\hline Control & $27.70 \pm 3.42$ & & $27.198 \pm 3.04$ \\
\hline
\end{tabular}

The Mean and SD of BMI at the baseline 6 months after intervention is shown in Table 2. The Kolmogorov-Smirnov test showed that the BMI had a normal distribution $(\mathrm{P}>0.05)$. The result of Analysis of Covariance (ANCOVA) showed although BMI decreased in 6 months after intervention, there wasn't significant difference in BMI 6 months after the intervention after baseline BMI was adjusted $((\mathrm{F}(1,77)=0.326, \mathrm{P}=0.57$, Partial Eta Squares $=0.004$, R Squared of model $=0.483$ ).

\section{Discussion}

Our study described that SBI can promote ADL and decrease SLS among high-school students. Analysis of this study showed that based on SBI; ADL was lower mean before intervention (Table 1). ADL was significantly higher in the intervention group in comparison with the control group after the intervention $(p<0.001)$. In this research the increase in ADL match with the results of Susi Kriemler, et al. (Kriemler et al., 2010) and Jordan A. Carlson et al. (Carlson et al., 2016), Story Mary et al. (Story Mary, Karen, \& French, 2006 ), Lettlefold et al., Vander Ploeg et al.( Vander Ploeg, Mcgavock, Maximova, \& Veugelers, 2014).

It was determined that SLS significantly decreased 6 months after SBI in the intervention group. This is match with the results of Ruanqdaraqanon N, et al. (Melkevik, Torsheim, \& Iannotti, 2010; Ruangdaraganon, Kotchabhakdi, Udomsubpayakul, Kunanusont, \& Suriyawongpaisal, 2002; Patel et al., 2010; Sisson, Church, \& Martin, 2009; Swinbur, 2008b). Chi-square test showed significant differences in TVWT after SBI in the 
intervention group. This is also match with the results of Neumark-Sztainer et al. 2011, that SBI, at 9-month follow-up, intervention group reduced their SLS by almost one thirty-minute block a day $(p=.050)$ (Neumark-Sztainer et al., 2011). Based on research findings over TV watching hours are related with greater BMI (Swinburn \& Shelly, 2008; Blanck et al., 2007; Grontved, 2011; Swinburn, 2008a; Zimmerman, 2010). Although body mass index decreased in 3 and 6 months after intervention but there weren't significant differences between interventional and control groups. This is also match with the results of Paulo Henrique Guerra, et al. 2013 (Hong et al., 2016; Park, Bakhet, Karl, Yuan, \& Lonn, 2014; Guerra, Nobre, Silveira, \& Taddei, 2013; Schwartz, Leardo, Aneja, \& Elbel, 2016).

\section{Conclusion}

The present study determined the effect of SBI on obesity and overweight in students, parents, and school staff to decrease BMI and SLS and inactivity among students. When the performance of students on ADL and the positive effect of SBI on this matter are considered, one may conclude that SBI can pave the ground to boost ADL of the students and the society. They seem to exist enormous potential for schools to develop their role in providing students with extra ADL by building rapport with SBI providers of ADL. Schools can endow community-based organizations with their facilities during weekend, and holidays. Schools can cooperate in develop ADL programs to children and their parents. Considering the positive effect of SBI on the ADL, it seems that this type of intervention as one of the most important influencing factor can supply the necessary grounds for increasing ADL of the students and the society. Because of SLS and inactivity behaviors of the obese and overweight students, the obesity-related problems indicate the possibility of the students be susceptible to future health risks. It seems intervention strategies are warranted to reduce obesity and overweight in all children.

\section{Acknowledgments}

The authors appreciate the contribution of Dr. Mostafavi, Dr. Khalkhali, Dr. Parvaz, and administrators of educational districts of Urmia city, and Habibzadeh, Danesh, Ganbari, and Pishdad's high schools, and the support provided by their principals, assistants and teachers. We also gratefully thank all of the students from Urmia schools who assisted in conducting the questionnaire survey. This work was supported by the IUMS.

\section{Author Contributions}

BR conceived, designed and did data collection \& statistical analyses \& editing of manuscript.

FM helped to design the research, conduct the organization and coordination of the study, supervise the implementation process and draft the manuscript and to write the manuscript and conceive of the study.

HK helped to design and carry out the research, conduct the statistical analyses, write and revise the manuscript, advise us on the implementation process, and helped to revise the manuscript and participate in its design and advise us on the manuscript.

Ethical matters have been intended by the authors and there was no conflict of interest about the publication of this article.

\section{Competing Interests Statement}

The authors declare that there is no conflict of interests regarding the publication of this paper.

\section{References}

Asghar, R., Kourosh, S., Khairollah, A., Diana, S., Farhad, I., \& Sarokhani, M. (2015). Investigation of the Prevalence of Obesity in Iran: a Systematic Review and Meta-Analysis Study. Acta Medica Iranica, 53(10).

Baecke, J. A., Burema, J., \& Frijters, J. E. (1982). A short questionnaire for the measurement of habitual physical activity in epidemiological studies. . American Journal of Clinical Nutrition, 36, 936-942.

Blanck, H. M., Mccullough, M. L., Patel, A. V., Gillespie, C., Calle, E. E., \& Cokkinides, V. E., et al. (2007). Sedentary behavior, recreational physical activity, and 7-year weight gain among postmenopausal u.s. women. Obesity, 15(6), 1578-1588. http://dx.doi.org/10.1038/oby.2007.187

Carlson, J. A., Schipperijn, J., Kerr, J., Saelens, B. E., Natarajan, L., Frank, L. D., . . Sallis, J. F. (2016). Locations of Physical Activity as Assessed by GPS in Young Adolescents. Pediatric, 137(1).

De, O. M., Onyango, A. W., Borghi, E., Siyam, A., Nishida, C., \& Siekmann, J. (2007). Development of a who growth reference for school-aged children and adolescents. Bulletin of the World Health Organisation, 85(9), 660-667. http://dx.doi.org/10.2471/BLT.07.043497

Djalalinia, S., Qorbani, M., Peykari, N., \& Kelishadi, R. (2015). Health impacts of obesity. Pakistan Journal of 
Medical Sciences Online, 31(1), 239-242.

Grøntved, A., \& Hu, F. B. (2011). Television viewing and risk of type 2 diabetes, cardiovascular disease, and all-cause mortality: a meta-analysis. Jama, 305(23), 2448-2455. http://dx.doi.org/10.1001/jama.2011.812

Guerra, P. H., Nobre, M. R., Silveira, J. A., \& Taddei, J. A. (2013). The effect of school-based physical activity interventions on body mass index: A meta-analysis of randomized trials. Clinics, 68(9), 1263-73. http://dx.doi.org/10.6061/clinics/2013(09)14

Hong, M., Xiong, Y., Xie, S., Guo, S., Li, Y., Guo, B., \& Zhang, J. (2016). The impact of long-term school-based physical activity interventions on body mass index of primary school children-a meta-analysis of randomized controlled trials. BMC Public Health BMC series, 16, 205. http://dx.doi.org/10.1186/s12889-016-2829-z

Jafari-Adli, S., Jouyandeh, Z., Qorbani, M., Soroush, A., Larijani, B., \& Hasani-Ranjbar, S. (2014). Prevalence of obesity and overweight in adults and children in Iran; A systematic review. Journal of Diabetes \& Metabolic Disorders, 13(1), 1-10. http://dx.doi.org/10.1186/s40200-014-0121-2

Kriemler, S., Zahner, L., Schindler, C., Meyer, U., Hartmann, T., \& Hebestreit, H., et al. (2010). Effect of school based physical activity programme (kiss) on fitness and adiposity in primary schoolchildren: cluster randomised controlled trial. BMJ, 340 (feb23 1), c785. http://dx.doi.org/10.1136/bmj.c785

Mckenzie, T. L., Nader, P. R., Strikmiller, P. K., Yang, M., Stone, E. J., \& Perry, C. L., et al. (1996). School physical education: effect of the child and adolescent trial for cardiovascular health. Preventive Medicine, 25(4), 423. http://dx.doi.org/10.1006/pmed.1996.0074

Melkevik, O., Torsheim, T., Iannotti, R. J., \& Wold, B. (2010). Is spending time in screen-based sedentary behaviors associated with less physical activity: a cross national investigation. International Journal of Behavioral Nutrition \& Physical Activity, 7(3), 232-238. http://dx.doi.org/10.1186/1479-5868-7-46

Mirzaee Vishgaee, K. H., Rahmani Niya, F., \& AR., E. (2014). The relationship between nutritional knowledge, body composition and physical activity level in middle-aged, obese and underweight females. Journal of Sport in Biomotor Sciences, 10(2).

Neumark-Sztainer, D. R., Friend, S. E., Flattum, C. F., Hannan, P. J., Story, M. T., \& Bauer, K. W., et al. (2010). New moves - preventing weight-related problems in adolescent girls: A group-randomized study. American Journal of Preventive Medicine, 39(5), 421-32. http://dx.doi.org/10.1016/j.amepre.2010.07.017

Ono, R., Hirata, S., Yamada, M., Nishiyama, T., Kurosaka, M., \& Tamura, Y. (2007). Reliability and validity of the baecke physical activity questionnaire in adult women with hip disorders. Bmc Musculoskeletal Disorders, 8(16), 63-67. http://dx.doi.org/10.1186/1471-2474-8-61

Park, J. J., Bakhet, R., Karl, D., Yuan, F., \& Lonn, E. (2014). Abstract 17944: Effects of School-Based Interventions on Body Mass Index in Children and Adolescents: a Systematic Overview and Meta-analysis. 2012 IEEE 24th International Conference on Tools with Artificial Intelligence (pp.552-559). IEEE Computer Society.

Patel, A. V., Bernstein, L., Deka, A., Feigelson, H. S., Campbell, P. T., \& Gapstur, S. M., et al. (2010). Leisure time spent sitting in relation to total mortality in a prospective cohort of us adults. American Journal of Epidemiology, 172(4), 419-29. http://dx.doi.org/10.1093/aje/kwq155

Peter, S., \& Bandmann, E. (2008). Physical activity questionnaires, A critical review of methods used in validity and reproducibility studies. Sport Science and Health Science, 30-31.

Roya, K., Gelayol, A., Mostafa, Q., Asal, A.-J., Maryam, B., Mahnaz, T., . . Heshmat, R. (2013). Methodology and Early Findings of the Fourth Survey of Childhood and Adolescence Surveillance and Prevention of Adult Non-Communicable Disease in Iran: The CASPIAN-IV Study. Int J Prev Med. IJPM, 12, 1451-1460.

Ruangdaraganon, N., Kotchabhakdi, N., Udomsubpayakul, U., Kunanusont, C., \& Suriyawongpaisal, P. (2002). The association between television viewing and childhood obesity: a national survey in thailand. Journal of the Medical Association of Thailand = Chotmaihet thangphaet, 85 Suppl 4(supplement 4), 75-80.

Saris, W. H., Snel, P., Baecke, J., van Waesberghe, F., \& Binkhorst, R. A. (1977). A portable miniature solid-state heart rate recorder for monitoring daily physical activity. Biotelemetry, 4(3), 131-140.

Schwartz, A. E., Leardo, M., Aneja, S., \& Elbel, B. (2016). Effect of a School-Based Water Intervention on Child Body Mass Index and Obesity. JAMA Pediatr, 170(3), $220-226$. http://dx.doi.org/10.1001/jamapediatrics.2015.3778 
Sisson, S. B., Church, T. S., \& Martin, C. K., E. A. (2009). Profiles of sedentary behavior in children and adolescents: the US National Health and Nutrition Examination Survey, 2001-2006. Int J Pediatr Obes, 4, 353-359. http://dx.doi.org/10.3109/17477160902934777

Story Mary, Karen M. Kaphingst, \& French, S. (2006). The Role of Schools in Obesity Prevention. The Future of Children, 16(1), 109-142. http://dx.doi.org/10.1353/foc.2006.0007

Swinburn, B. \& Shelly, A. (2008). Effects of TV time and other sedentary pursuits. International Journal of Obesity \& Related Metabolic Disorders . 32, S132-S136. http://dx.doi.org/10.1038/ijo.2008.249

Tofighi, A., Babaei, S., Eloon Kashkuli, F., \& Babaei, R. (2014). The relationship between the amount of physical activity and general health in urmia medical university students. Journal of Urmia Nursing \& Midwifery Faculty, 12(3), 168.

Vander Ploeg, K. A., Mcgavock, J., Maximova, K., \& Veugelers, P. J. (2014). School-based health promotion and physical activity during and after school hours. Pediatrics, 133(2), 371-8. http://dx.doi.org/10.1542/peds.2013-2383

Zimmerman, F. J., \& Bell, J. F. (2010). Associations of television content type and obesity in children. American Journal of Public Health, 100(2), 334-340. http://dx.doi.org/10.2105/AJPH.2008.155119

\section{Copyrights}

Copyright for this article is retained by the author(s), with first publication rights granted to the journal.

This is an open-access article distributed under the terms and conditions of the Creative Commons Attribution license (http://creativecommons.org/licenses/by/4.0/). 